\title{
Pressure of Local Anesthetic Solution While Performing Sciatic Nerve Blockade in Human Subgluteal Area
}

\author{
Zakhar Kokhan, Andrei Brukhnou, Aliaksei Marochkov, Valery Piacherski \\ Department of Anaesthesiology and Intensive Care, Mogilev Regional Hospital, Mogilev, Republic of Belarus \\ Email: coxann@yandex.ru
}

Received 14 September 2014; revised 18 October 2014; accepted 1 November 2014

Copyright (C) 2014 by authors and Scientific Research Publishing Inc.

This work is licensed under the Creative Commons Attribution International License (CC BY). http://creativecommons.org/licenses/by/4.0/

(c) () Open Access

\begin{abstract}
Intraneural introduction of local anesthetic belongs to the existing complications of peripheral nerves blockades. The damage of peripheral nerves is associated with the damaging effect of the injection needle and with the pressure caused by the introduction of local anesthetic. Purpose: Determine the pressure of the local anesthetic in fascial compartment of the sciatic nerve during his administration in the blockade of the sciatic nerve subgluteal access. Materials and Methods: Submitted blockade of the sciatic nerve subgluteal access in 22 patients with peripheral nerve electrostimulation under ultrasound guidance. To measure interstitial pressure system was used with the inclusion of a probe invasive blood pressure. Results: During the introduction of $1 \mathrm{ml}$ in the fascial compartment of the sciatic nerve, the pressure of $0.77 \mathrm{psi}(40 \mathrm{mmHg})$ was registered. In the course of the further introduction of local anesthetic up to $13 \mathrm{ml}$, the pressure did not alter validly $(p>0.05)$ and its average was $40(35 ; 45) \mathrm{mmHg}$ or $0.77(0.68 ; 0.87)$ psi. This is the first study that has allowed to determine the pressure of local anesthetic in the fascial compartment of the sciatic nerve at the time of its introduction, the blockade of the sciatic nerve subgluteal access for the first time determined the probable maximum pressure intraneural injection of local anesthetic. The disadvantage of this study is that it is impossible to measure the pressure of administration over $5.8 \mathrm{psi}(300 \mathrm{mmHg})$, and the lack of opportunity to assess the intraneural blood flow in the sciatic nerve during the creation of such pressure.
\end{abstract}

\section{Keywords}

Peripheral Blockade, Sciatic Nerve, Pressure of the Local Anestnetic, Ultrasound Guidance

\section{Introduction}

Intraneural introduction of local anesthetic belongs to the existing complications of peripheral nerves blockades

How to cite this paper: Kokhan, Z., Brukhnou, A., Marochkov, A. and Piacherski, V. (2014) Pressure of Local Anesthetic Solution While Performing Sciatic Nerve Blockade in Human Subgluteal Area. Open Journal of Anesthesiology, 4, 276-280.

http://dx.doi.org/10.4236/ojanes.2014.411040 
[1]. The application of electrostimulation of peripheral nerves does not exclude intraneural introduction of local anesthetic [2]. The damage of peripheral nerves is associated with the damaging effect of the injection needle [3] and with the pressure caused by the introduction of local anesthetic. Dogs intraneural pressure was measured [3]. The data obtained prove that the nerve pressure higher than 25 psi involves neurologic disorders of the nerve anatomic structure and neurologic deficit.

Some attempts have been made to define anesthesiologist's influence on the pressure of local anesthetic introduction while performing blockades of peripheral nerves in vitro [4]. The pressure in the fascial compartment of the sciatic nerve has not been defined yet. The level of pressure with an unpremeditated intraneural position of the injection needle is not known as well.

\section{Materials and Methods}

The research was carried out with the permission of Ethics Committee at Health Care Institution "Mogilev Regional Hospital”, protocol No. 31 dated 14 April 2013. From 21.12.12 to 16.06.13, we conducted a prospective research to measure the pressure in the fascial compartment of 22 patients while blocking their sciatic nerve in subgluteal area. In all cases preliminarily a patient's consent was received.

The age of the patients was $47.4 \pm 15.9$. 7 male and 15 female patients were involved in the study.

All patients had surgeries of traumatic injuries and dysfunctions of lower extremities, removal of metal after osteosynthesis of foot, shin and ankle.

The exclusion criteria were patient's refusal of application of the proposed form of anesthesia, age $<18$ years, weight $<50 \mathrm{~kg}$, physical status score for ASA $>3$, a history of allergic reactions to the used local anesthetics and other drugs, coagulopathy, neurological or neuro-muscle diseases, severe liver diseases, kidney failures, inability to cooperate with the patient.

20 - 30 min before the block 0.5 - $0.8 \mathrm{mg}$ of atropine and $10 \mathrm{mg}$ of diphenhydramine were injected intramuscularly. All patients had sedation with $0.1 \mathrm{mg}$ of fentanyl intravenously.

To provide intraoperative anesthesia all blockades of the sciatic nerve were carried out with $15 \mathrm{ml}$ of $0.75 \%$ solution of ropivacaine. $2 \mathrm{ml}$ of the solution filled the system, $13 \mathrm{ml}$ were introduced into the fascial compartment of the sciatic nerve. We applied this volume because earlier we had stated that for an effective blockade of the sciatic nerve $5 \mathrm{ml}$ of $0.75 \%$ solution of ropivacaine [5], or $12.5 \mathrm{ml}$ of $1 \%$ solution of lidocaine [6] are enough. Thus we define the pressure of the introduction for different minimal effective volumes of $0.75 \%$ solution of ropivacaine and $1 \%$ solution of lidocaine. Alongside with the blockade of the sciatic nerve the block of the patients' femoral nerve was performed.

The measurement of the local anesthetic pressure in the course of the sciatic nerve blockade was carried out in the following way. Firstly, the system was installed. It consisted of: a) a $100 \mathrm{~mm}$ long injection needle (B|Braun Stimuplex $^{\circledR}$ A, $\left.21 \mathrm{G} \times 4,0.80 \times 100 \mathrm{~mm}\right)$; b) an electrostimulator of peripheral nerves (B|Braun Stimuplex ${ }^{\circledR}$ DigRC, Germany) which produces electric current pulses with the current frequency $1-2 \mathrm{~Hz}$ and current strength up to $5 \mathrm{~mA}$; c) a $20 \mathrm{ml}$ syringe with $0.75 \%$ solution of ropivacaine; d) an infusional conductor; e) a stepper infusional pump; f) a sensor of invasive blood pressure and a hemodynamic monitor "Integral" with the block to measure invasive pressure.

To perform a block we measured the initial blood pressure which was created in the installed system during the titration of local anesthetic. This pressure was fixed. Then we excluded the pressure of the system from the further measurements. Later a patient was placed in the prone position. After the management of the operative site in aseptic conditions with an injection needle connected to the stimulator of peripheral nerves and the system measuring the pressure we started the performance of blocks. To verify the needle position ultrasound guidance was applied, then a test-dose of $0.5-1 \mathrm{ml}$ was introduced. The introduction of local anesthetic preceded with the speed $5 \mathrm{ml}$ per min. During the introduction of local anesthetic through the infusional conductor the pressure was created in the system and it was fixed by the sensor of invasive blood pressure and reflected on the screen of the hemodynamic monitor "Integral". Under ultrasound guidance the spread of local anesthetic was defined. The interstitial pressure was measured in real-time mode and the data were then noted down in the protocol of the research and in the Anesthesia Protocol after the introduction of each ml of local anesthetic. At the same time the value on the monitor was reduced in accordance with the value reflecting the resistance of the installed system by the formula:

$$
\mathrm{P}=\mathrm{P}(\text { })-\mathrm{P}(\text { of the system }),
$$


where $\mathrm{P}$ stands for the interstitial pressure value, $\mathrm{P}(m)$ is the general value of the interstitial pressure and the resistance of the installed system reflected on the screen during measuring procedures, $\mathrm{P}$ (of the system) is the pressure of the system during the introduction of local anesthetic solution.

For visualization of the nerve trunk the ultrasound machine "Alока SSC400" with the ultrasound transducer of 7.5 MHz was used. The ultrasound scanning made it possible to control the spread of local anesthetic around and along the nerve.

Statistical data processing was performed using the program Statistica 7.0. Statistical significance of the differences of the average figures was assessed with the help of the nonparametic analysis (Kruskal-WalllisANOVA). The differences between the groups were considered valid with $\mathrm{p}<0.05$.

\section{Results}

During the introduction of $1 \mathrm{ml}$ in the fascial compartment of the sciatic nerve the pressure of $0.77 \mathrm{psi}$ (40 $\mathrm{mmHg}$ ) was registered. In the course of the further introduction of local anesthetic up to $13 \mathrm{ml}$ the pressure did not alter validly $(\mathrm{p}>0.05)$ (Figure 1$)$ and its average was $40(35 ; 45) \mathrm{mmHg}$ or $0.77(0.68 ; 0.87)$ psi (Table 1$)$. In 7 cases an initial unpremeditated intraneural position of the injection needle was noted. With the introduction of the local anesthetic solution the pressure of these patients was $>5.8 \mathrm{psi}$ ( $>300 \mathrm{mmHg}$ ). The performance characteristics of the monitor did not allow the measurement of the pressure higher than $5.8 \mathrm{psi}(300 \mathrm{mmHg})$. In such cases the position of the injection needle was corrected and local anesthetic was introduced into the fascial compartment of the sciatic nerve. Thus intraneuraly we did not inject more than $2.5 \mathrm{ml}$. After the correction of the injection needle the pressure in the fascial compartment of such patients was $0.58-1.2 \mathrm{psi}(30-60 \mathrm{mmHg})$.

All 22 patients had complete sensor and motor blockades.

\section{Discussion}

In 2004 in the article Hadzic et al. [3] displayed the pressure changes depending on the perineural or intraneural position of the injection needle. The data were $\leq 4$ and $\geq 25$ psi. With $\geq 25$ psi the histological study of the dogs

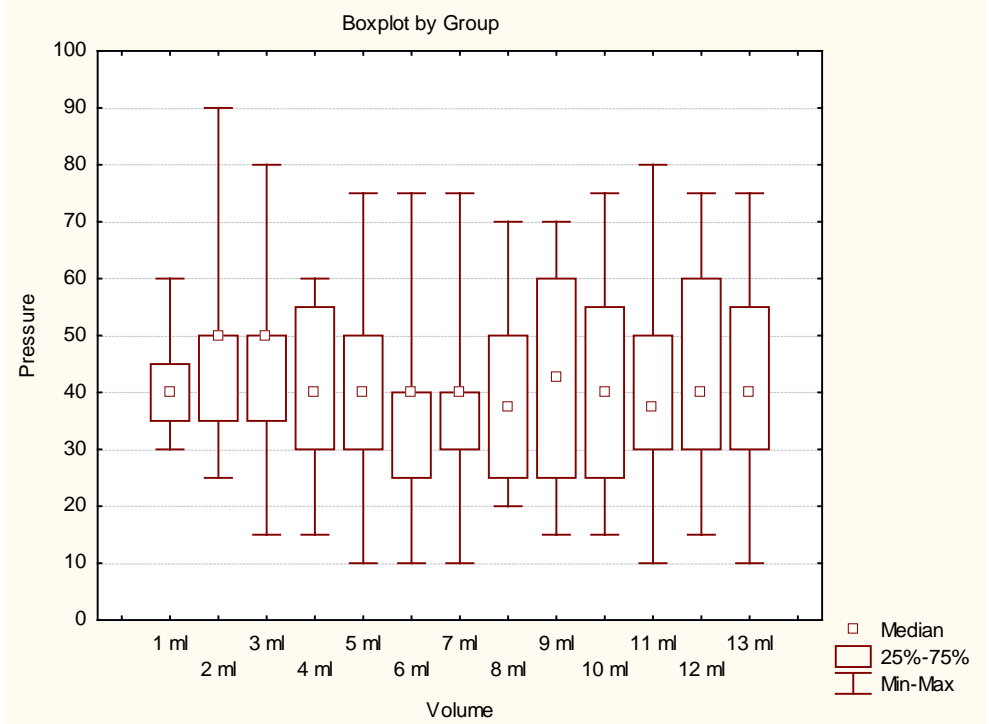

Figure 1. Dynamics of the interstitial pressure.

Table 1. Average pressure at each stage of the introduction.

\begin{tabular}{|c|c|c|c|c|c|c|c|c|c|c|c|c|c|}
\hline Volume, ml & 1 & 2 & 3 & 4 & 5 & 6 & 7 & 8 & 9 & 10 & 11 & 12 & 13 \\
\hline Pressure, mmHg & 40 & 50 & 50 & 40 & 40 & 40 & 40 & 37.5 & 42.5 & 40 & 37.5 & 40 & 40 \\
\hline Pressure, PSI & 0.77 & 0.97 & 0.97 & 0.77 & 0.77 & 0.77 & 0.77 & 0.73 & 0.82 & 0.77 & 0.73 & 0.77 & 0.77 \\
\hline
\end{tabular}


indicated degenerative changes in axons and disorders in the sciatic nerve structure. But the authors did not measure the pressure in the fascial compartment of the sciatic nerve [3]. Our data have shown that with the intraneural introduction during the injection of $2.5 \mathrm{ml}$ the pressure was higher than 5.8 psi. We can assume that the results of our research on the pressure of the local anesthetic introduction into the sciatic nerve are comparable with the data obtained by Hadzic et al. who studied dogs. However, the maximal pressure was not measured because of the monitor performance characteristics. In our research, the pressure of the intraneural introduction exceeded the introduction into the fascial compartment of the sciatic nerve by $4.64-5.22$ psi. Our data were comparable with the results acquired by Hadzic et al. because the studies had similar conditions (the diameter of the needles was $21 \mathrm{G}$ for people and 25G for dogs, the speed of the local anesthetic introduction was $5 \mathrm{ml} / \mathrm{min}$ for people and $4 \mathrm{ml} / \mathrm{min}$ for dogs). At the same time, the data may differ as the human sciatic nerve is larger than the dog's sciatic nerve. In the experiment conducted by Hadzic et al. the nerve was obtained surgically and the needle was sewed into it. At the injection site of the dogs there was no pressure of the surrounding tissues on the nerve when local anesthetic was introduced. Even if we assume that the sciatic nerve had not been obtained surgically, the pressure of the introduction for dogs could not be extrapolated to men as the mass of the surrounding tissues is significantly larger than that of the dogs. That's why the pressure of the intraneural local anesthetic introduction is probably higher than $5.8 \mathrm{psi}(300 \mathrm{mmHg})$ registered in our study. The performance characteristics of the hemodynamic monitor did not allow the measurement of the maximal pressure of the local anesthetic introduction. But it has been definitely stated that this pressure exceeds $5.8 \mathrm{psi}(300 \mathrm{mmHg})$. The dogs with such pressure during the introduction of the rated dose demonstrated neurologic deficit. In our research the unpremeditated maximal intraneural introduction of local anesthetic did not exceed $2.5 \mathrm{ml}$. During the postoperative period complications and neurologic disorders were not registered. Probably with the introduction of all $13 \mathrm{ml}$ intraneuraly the pressure might exceed $5.8 \mathrm{psi}(300 \mathrm{mmHg}$ ) which would involve neurologic deficit during the postoperative period the way it was noted by Hadzic et al.

Gadsden et al. proved that during the interscalene blockade of the brachial plexus which involved the contacts of the needle with the roots of the brachial plexus the pressure was $\geq 15$ psi. The comparison of the data acquired in our study and obtained by Gadsden $e t$ al. were not correct as the speed of the introduction in the study by Gadsden et al. was $10 \mathrm{ml} / \mathrm{min}$ and the anatomic architecture of the brachial plexus and the sciatic nerve differ [7]-[9].

This was the first research which allowed the definition of the local anesthetic pressure in the fascial compartment of the sciatic nerve while the blockade of the sciatic nerve was carried out in the subgluteal area. It is the research which for the first time states the probable maximal pressure during the intraneural introduction of local anesthetic. The drawback of the research is the inability to measure the pressure higher than 5.8 psi (300 $\mathrm{mmHg}$ ) as well as the impossibility to assess the intraneural blood flow in the sciatic nerve under such pressure.

\section{References}

[1] Fredrickson, M.J. and Kilfoyle, D.H. (2009) Neurological Complication Analysis of 1000 Ultrasound Guided Peripheral Nerve Blocks for Elective Orthopaedicsurgery: A Prospective Study. Anaesthesia, 64, 836-844. http://dx.doi.org/10.1111/j.1365-2044.2009.05938.x

[2] Robards, C., Hadzic, A., Somasundaram, L., Iwata, T., Gadsden, J., Xu, D. and Sala-Blanch, X. (2009) Intraneural Injection with Low-Current Stimulation during Popliteal Sciatic Nerve Block. Anesthesia \& Analgesia, 109, 673-677. http://dx.doi.org/10.1213/ane.0b013e3181aa2d73

[3] Hadzic, A., Dilberovic, F., Shah, S., Kulenovic, A., Kapur, E., Zaciragic, A., Cosovic, E., Vuckovic, I., Divanovic, K.A., Mornjakovic, Z., Thys, D.M. and Santos, A.C. (2004) Combination of Intraneural Injection and High Injection Pressure Leads to Fascicular Injury and Neurologic Deficits in Dogs. Regional Anesthesia and Pain Medicine Journal, 29, 417-423.

[4] Claudio, R., Hadzic, A., Shin, H., Vloka, J.D., Castro, J., Koscielniak-Nielsen, Z., Thys, D.M. and Santos, A.C. (2004) Injection Pressures by Anesthesiologists during Simulated Peripheral Nerve Block. Regional Anesthesia and Pain Medicine Journal, 29, 201-205.

[5] Piacherski, V. and Marochkov, A. (2013) A Comparison of the Onset Time of Complete Blockade of the Sciatic Nerve in the Application of Ropivacaine and Its Equal Volumes Mixture with Lidocaine: A Double-Blind Randomized Study. Korean Journal of Anesthesiology, 65, 42-47. http://dx.doi.org/10.4097/kjae.2013.65.1.42

[6] Piacherski, V. and Marachkou, A. (2014) Features and Principles the Spread of Local Anesthetic Blockade of the Sciatic Nerve at Depends on the Amount of Anesthetic. Open Journal of Anesthesiology, 4, 31-35. 
[7] Gadsden, J.C., Choi, J.J., Lin, E. and Robinson, A. (2014) Opening Injection Pressure Consistently Detects NeedleNerve Contact during Ultrasound-Guided Interscalene Brachial Plexus Block. Anesthesiology, 120, 1246-1253. http://dx.doi.org/10.1097/ALN.0000000000000133

[8] Moayeri, N., Bigeleisen, P.E. and Groen, G.J. (2008) Quantitative Architecture of the Brachial Plexus and Surrounding Compartments, and Their Possible Significance for Plexus Blocks. Anesthesiology, 108, 299-304.

[9] Moayeri, N. and Groen, G.J. (2009) Differences in Quantitative Architecture of Sciatic Nerve May Explain Differences in Potential Vulnerability to Nerve Injury, Onset Time, and Minimum Effective Anesthetic Volume. Anesthesiology, 111, 1128-1134. http://dx.doi.org/10.1097/ALN.0b013e3181bbc72a 
Scientific Research Publishing (SCIRP) is one of the largest Open Access journal publishers. It is currently publishing more than 200 open access, online, peer-reviewed journals covering a wide range of academic disciplines. SCIRP serves the worldwide academic communities and contributes to the progress and application of science with its publication.

Other selected journals from SCIRP are listed as below. Submit your manuscript to us via either submit@scirp.org or Online Submission Portal.
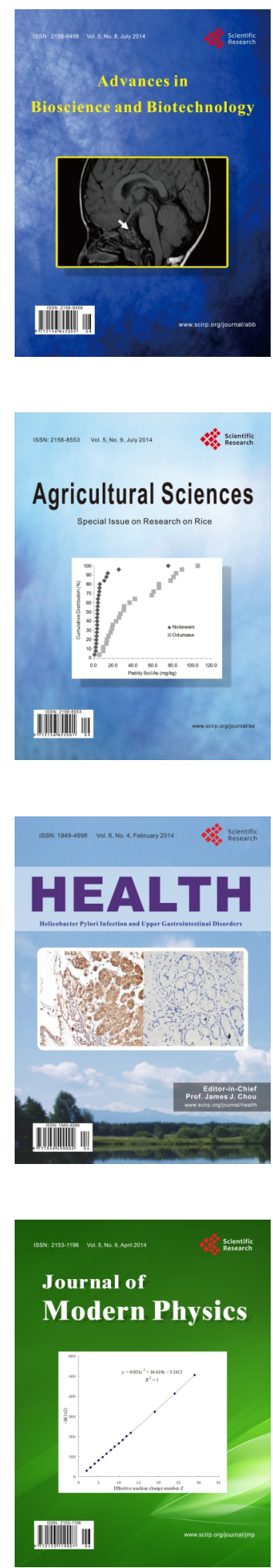
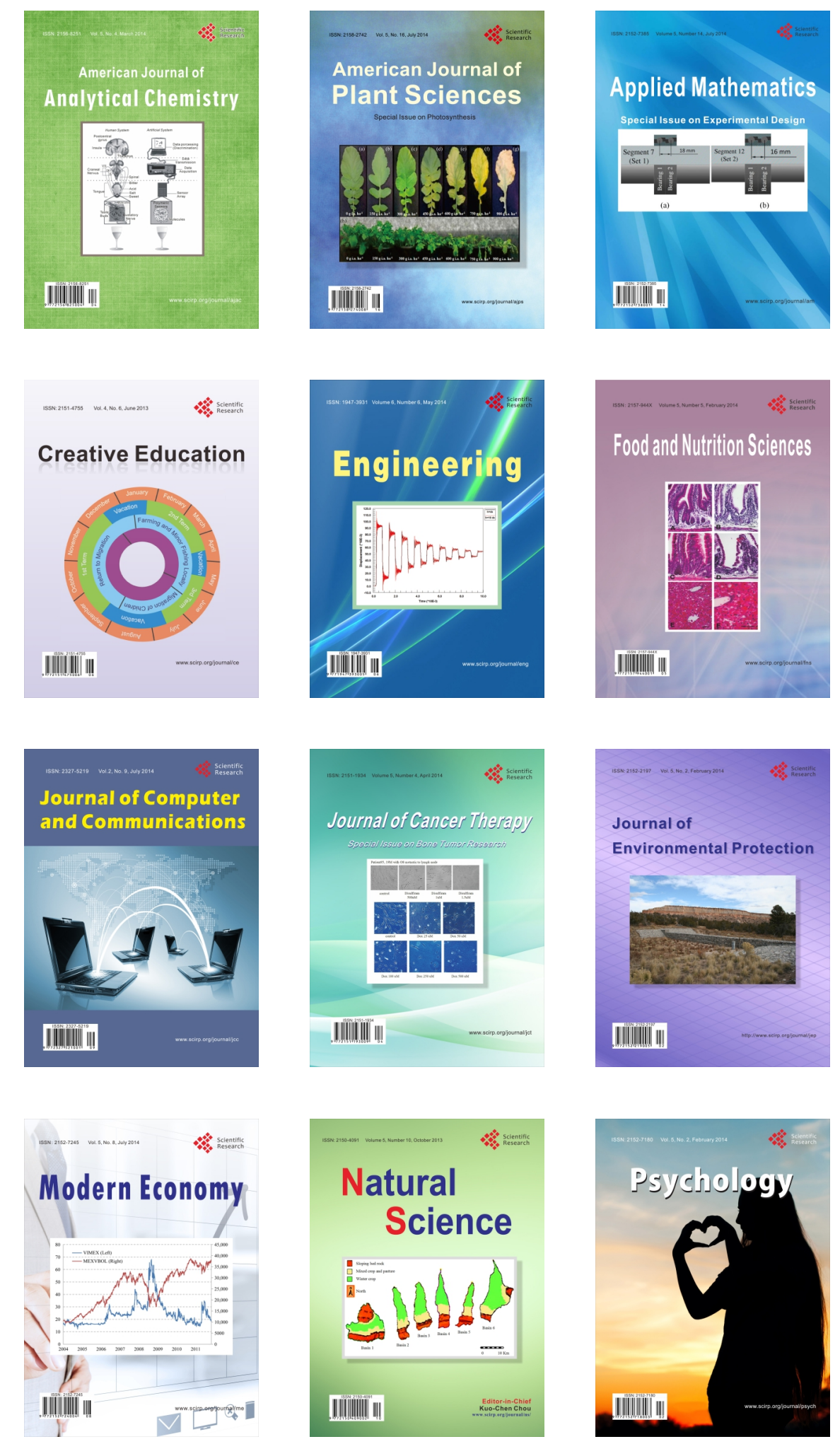